\title{
HABITAT SUITABILITY MODELING FOR EXPLORATION OF THE SPATIAL DISTRIBUTION OF KASHMIR MUSK DEER IN DACHIGAM NATIONAL PARK, KASHMIR
}

\author{
Mudasir Ali \\ Department of Environmental Sciences, \\ University of Kashmir, Srinagar-190006, Kashmir, J and K, Wild Defenders, Kashmir
}

Received 2014-01-25; Revised 2014-02-12; Accepted 2014-08-18

\begin{abstract}
Musk deer are highly important as a medicinal species that are severely exploited throughout their range of occurrence due to the medicinal value of the musk produced only by the male individuals. Methods used for studying the populations and distributions of other ungulates do not work well with musk deer and the presence of a unified methodology for studying musk deer appear to be lacking worldwide. Therefore, the development of a simple predictive model for studying the distribution of the musk deer habitats stands as an important task to be accomplished. Two kinds of research questions were pursued during the present study-examining through field research what kind of habitat musk deer used and mapping the habitat in the park using a GIS and remote sensing environment. The parameters which were found to have a profound influence in predicting the species's spatial distribution have been used in the modeling of the current habitat suitability for the Kashmir musk deer (Moschus cupreus). The study was conducted at the upper reaches (elevations $2200 \mathrm{~m}$ and above) of the Dachigam National Park, Kashmir $\left(34^{\circ} 05^{\prime} 18.40^{\prime \prime} \mathrm{N}\right.$ $34^{\circ} 06^{\prime} 04.69^{\prime \prime} \mathrm{N}$ and $\left.75^{\circ} 03^{\prime} 32.05^{\prime \prime} \mathrm{E}-75^{\circ} 04^{\prime} 27.26^{\prime \prime} \mathrm{E}\right)$ during January 2005 -January 2008 to evaluate the characteristics of the musk deer habitats. The environmental attributes which were found to have a profound influence in predicting the species's spatial distribution included the slope exposures in the range of $293^{\circ}$ Northwest $-68^{\circ}$ Northeast, slope gradients of $25-40^{\circ}$ and elevations of $2100 \mathrm{~m}$ and above, with the preference ratings of aspect > slope > elevation and, therefore, were considered for the development of the habitat suitability model for prediction of the spatial distribution of the Kashmir musk deer. The current suitable musk deer habitat in Dachigam National Park is estimated in the extent of about 40 sq. $\mathrm{km}$. ( $28 \%$ area of the national park). The model results were found to have a good performance in making fair predictions (about 50\% area of the National Park has been validated for predictions). The spatial distribution of musk deer reflected the musk deer habitats mostly spread through the Picea smithiana and blue pine forest and some habitats close to the alpine scrub nearby to the rocky cliffs. The potential of the model has been utilized in finding the density of musk deer. Possible 60 musk deer survive in Dachigam National Park with a density of 0.42 individuals per sq. km. However, the weighted mean density in the musk deer habitats was about 1.55 individuals per sq. $\mathrm{km}$.
\end{abstract}

Keywords: Current Habitat Suitability, Environmental Variables, GIS Environment, Musk Deer, Predictive Modeling, Spatial Predictions

\section{INTRODUCTION}

\subsection{Background}

Musk is highly prized in Traditional East Asian Medicine (TEAM), accounting for more than $90 \%$ of the total musk market, which uses musk in more than 400 pharmaceutical preparations to treat illnesses ranging from heart disease to diseases of the nervous system (WWF, 2002). It is an ingredient in more than 200 different medicines in Japan (BOSTID, 1991). The fragrancy of Musk has been under appreciation from pre-historic times; 
however, the use of musk in the perfumery is not of a massive magnitude and does not apparently pose any incremental threat to the populations of musk deer. The use of musk in the medicines is the biggest challenge to the survival of the musk deer.

Musk deer are of moderate size with an average mature weight of about $6-11 \mathrm{~kg}$ and a body length of $50-90 \mathrm{~cm}$ and stand 50-60 cm high at the shoulder and about $5 \mathrm{~cm}$ higher at the rump (BOSTID, 1991). The musk pod located on the abdomen in the male individuals contains a soft, brownish matter which is the much coveted musk; about $24 \mathrm{~g}$ is the limit of the weight (Ward, in Lawrence, 1895). Strongly territorial, musk-deer keep their territories all the year round and also fighting over them (Burton and Burton, 1990). Musk deer occur in at least 13 countries in Asia including the Russian Far East-Afghanistan, Kazakhstan, Russia, Mongolia, China, North and South Korea, Vietnam, Myanmar, Bhutan, Nepal, India, Jammu and Kashmir, Pakistan and possibly Kyrgyzstan. The total global population of the musk deer is believed to be likely between 400,000 and 800,000; with largest numbers found in China, Russia and Mongolia (WWF, 2002), however, the updated population estimates appear to be lacking worldwide. The habitat preferences for rocky terrain at elevations between 2,200 $\mathrm{m}$ and 4,300 $\mathrm{m}$ within the upper forest and scrub zones are exhibited by the Himalayan musk deer (Schaller, 1989). The musk deer is found in the forests, open scrub and alpine areas of Jammu and Kashmir except Ladakh at above $2400 \mathrm{~m}$ (Gergan, 1962).

Models predicting species spatial distributionsometimes called resource selection function or habitat suitability models-are increasingly applied to wildlife management issues (Hirzel et al., 2006). 'Current habitat suitability' is employed to estimate the current ability of a spatial unit to provide the conditions (i.e., food, water and cover) for an organism's survival and perpetuation. It reflects existing conditions, such as vegetation cover determined by natural and anthropogenic disturbance (Stelfox, 1991). Any habitat model such as a 'habitat suitability index' directly or indirectly attempts to capture the fitness relationship between an animal and its habitat (Mitchell et al., 2002). The work of (Hirzel et al., 2006) has shown that evaluating a habitat suitability model based only on presences is possible and is a valuable exercise.

Satellite data-based estimates have shown potential for predicting the presence of Myanmar's endangered Eld's deer (Cervus eldi) using Landsat Enhanced Thematic Mapper (ETM+) imagery to delineate the habitat (Koy et al., 2005). The status and the effect of potential remaining habitat of the Eld's deer have been mapped on landcover maps derived from satellite imagery (McShea et al., 1999). Besides the use of Landsat TM/ETM+images in detection of land use changes (Madugundu et al., 2014), Landsat images have also been used for quantifying pampas deer (Ozotoceros bezoarticus celer) habitat abundance and rates of loss due to replacement and habitat changes (Demaría et al., 2003). Landsat TM imagery has been successfully used for vegetation and landcover mapping (Lillesand and Kiefer, 1994). Land remote sensing satellite (Landsat) thematic mapper data has also been used by (Bond et al., 2006) for geospatial analyses to infer population extinction in mygalomorph spiders endemic to the Los Angeles region. Geographic information systems find use in a variety of environmental analyses (for example, analysis of various landform characteristics by (Akawwi, 2013). Based on the presence and absence data, the treatment of various habitat features (like terrain elevation, slope pattern, forest type) has also been satisfactorily performed in a GIS environment for the estimation of density and population size of elephants in Sabah, Malaysia (Alfred et al., 2010).

\subsection{Research Gap}

Habitat suitability index models are spatially informed, meaning that spatial orientation and configurations of key habitat components are important (Powell et al., 1997). However, the number of variables used in the habitat suitability index models is usually high, raising questions about parsimony and ease of use by managers. Too much detail makes a model difficult to parameterize and to validate (Beck, 1983; Ludwig and Walters, 1985; DeAngelis et al., 1990). An active area of research therefore considers how to reduce model complexity while retaining essential system behavior (Rastetter et al., 1992; Cale, 1995). Strictly from the perspective of how input variables shape habitat suitability index calculations, future improvements of the habitat suitability index could focus on those components observed to have the greatest sensitivities and elasticities, although this would not necessarily improve biological meaning of the model (Mitchell et al., 2002).

No detailed study has been conducted till date on the musk deer in Kashmir and the present study is first of its kind to be explored. The IUCN red data list of threatened species 2014 recognizes Kashmir musk deer (Moschus cupreus) as "endangered" and remarks about the species as "nothing appears to be known of this species's habitat 
or ecology". Therefore, the present study on the characteristics of the musk deer habitats and development of current habitat suitability model for the prediction of spatial distribution of musk deer in Dachigam National Park, Kashmir is a new endeavor.

\section{MATERIALS AND METHODS}

\subsection{Study Site}

Dachigam National Park, located some $21 \mathrm{~km}$ north-east of the Srinagar city of the Kashmir division (Jammu and Kashmir), comprised the study area and various study sites were selected for drawing a continuous data (Fig. 1 and 2). This national park draws special attention and significance because it harbors the flagship species Kashmir red deer (Cervus hanglu). Forming the north-west division of the Central Himalayan Mountain, Dachigam National Park comprises the Himalayan Highland biogeographical province and represents two biomes: Biome-5 Eurasian High Montane (Alpine and Tibetan) above c. $3600 \mathrm{~m}$ and Biome-7 Sino-Himalayan Temperate Forest, between $c .1800$ and $3600 \mathrm{~m}$.

Officially the area of the national park is recorded as $141 \mathrm{sq}$. km. but recently the estimates obtained from the satellite images report a slightly larger area. The elevations vary from 1642-4289 m. Preliminary field surveys were carried out and the sampling sites were selected mainly on the basis of the presence of droppings of musk deer. The study sites which were selected for drawing a continuous data included: Zahil, KungWattan, Kutnar and KawNar. These sites comprised the compartments 6, 7 and 8 (Zahil up to KawNar) of the Dachigam National Park. The area of the study plot was $6 \mathrm{~km}^{2}$ and the sites were located at least a kilometer apart from each other. Additional areas were extensively explored for studying the habitat features for the habitat suitability analysis.

Based on the data of Srinagar Meteorological Station, the average annual temperature and precipitation for the period of four years, January 2004 to December 2007 , was $14.17^{\circ} \mathrm{C}(2004=$ $14.41^{\circ} \mathrm{C} ; 2005=13.56^{\circ} \mathrm{C} ; 2006=14.38^{\circ} \mathrm{C} ; 2007=$ $\left.14.32^{\circ} \mathrm{C}\right)$ and $662 \mathrm{~mm}(2004=63.52 \mathrm{~cm} ; 2005=$ $68.08 \mathrm{~cm} ; 2006=83.13 \mathrm{~cm} ; 2007=50.18 \mathrm{~cm}$ ) respectively. Long-term data for the Kashmir region shows that the minimum temperature has risen by $\sim 2^{\circ} \mathrm{C}$ in December and $\sim 1.4^{\circ} \mathrm{C}$ in February over the last century, indicating warmer winters and earlier thawing of winter snow (Choudhury et al., 2008).

\subsection{Data Collection and Analysis of Environmental Parameters}

The elevation and location of the necessary points over which range of musk deer activities were detected in the musk deer habitats was recorded with a 12 channel Garmin GPS receiver (model: eTrex Legend), making sure that the positional error was below $6 \mathrm{~m}$. Slope exposure was observed utilizing a compass. An Abney level was used for the estimation of the steepness of the slope (Jones and Reynolds, 1996). The $10 \mathrm{~cm}$ long level was supported against the slope with twigs, pebbles. So that it was in a level position and the distance between the ground and the level at the $10 \mathrm{~cm}$ distance from either side was measured with the help of geometric dividers. The resulting measurements were drawn accurately on a paper and the angle was measured using a protractor. In this manner, the data range which covered all the necessary information (elevation, location, slope exposure and slope steepness) of the musk deer habitat was developed.

The imaging programs used in the study included Arc Gis-9.2, Erdas Imagine-9.0 and Arc View-3.2a. The boundary of the study area was delineated with Survey Of India (SOI) Toposheet (scale 1:50,000) while as the landcover data was based on LANDSAT ETM+ image acquired on 15th of October 2001 and 1:50,000 SOI topographic map. Training sets were generated and supervised classification was performed to delineate various forest type classes. The slope gradient, aspect, terrain and elevation maps of the area were generated from Shuttle Radar Topographic Mission (SRTM) data of $90 \mathrm{~m}$ resolution, available at the Global Landcover Facility (www.landcover.org). Each of the themes with its associated attribute data were digitally encoded in GIS data base. Rules and criteria used in habitat modeling were framed in accordance with the field evaluation for the environmental data. Each factor was mapped and assigned a thematic layer in the GIS. The derived maps were rasterized, reclassified and spatial analysis was performed to obtain the results (Fig. 3).

The aspect or slope exposures in the range of $293^{\circ}$ Northwest $-68^{\circ}$ Northeast, slope gradients of $25^{\circ}$ $40^{\circ}$ and elevations $2100 \mathrm{~m}$ and above were considered for the development of the habitat suitability model for prediction of the spatial distribution of the musk deer in Dachigam National Park. Using Raster Calculator from the Spatial Analyst Tool of the Arc Map program, the habitat suitability map was prepared by merging the individual predictor or favorable components and extracting the overlapped regions. The preference was rated as "Aspect $=1$ and Slope $=2$ and Elevation $=3$ " for building the habitat suitability model. 


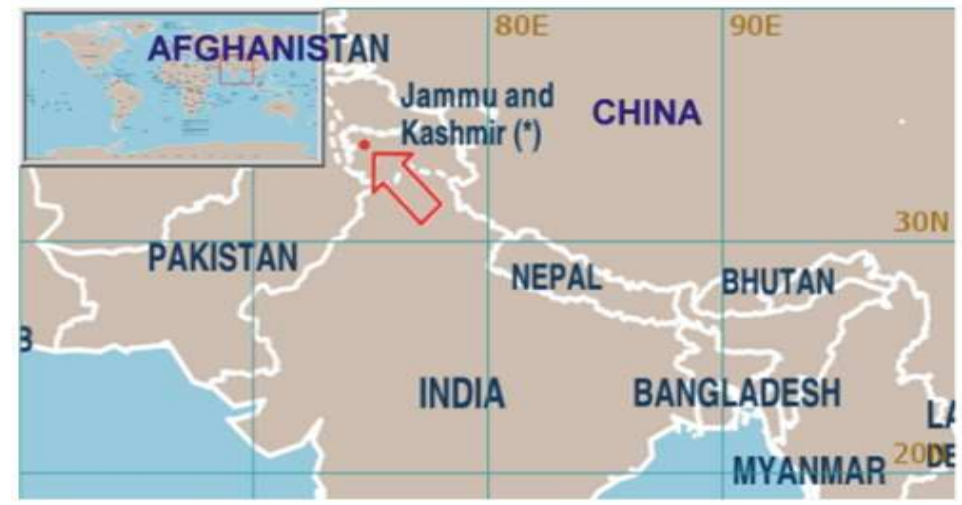

Courtesy: Department of Peacekeeping Operations, Cartographic Section, United Nations

Fig. 1. Study area highlighted on the location map of Jammu \& Kashmir

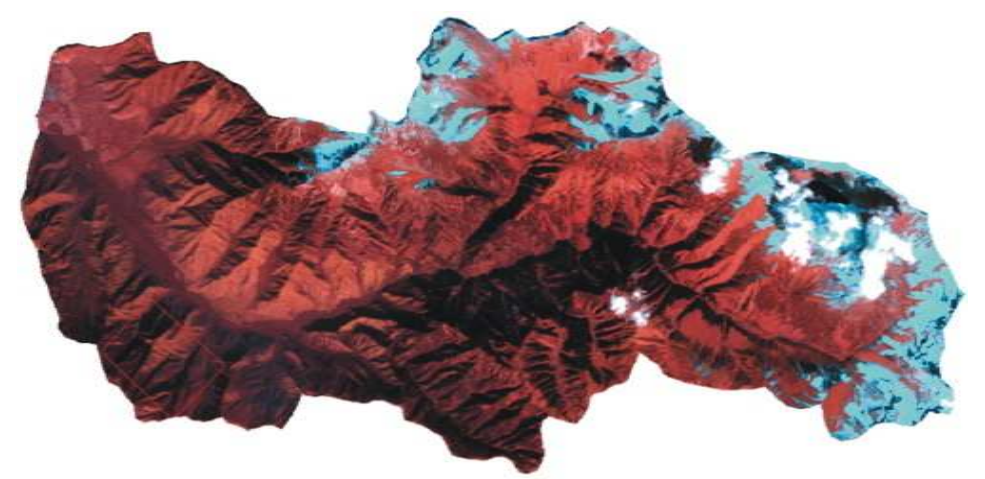

Fig. 2. Image of the study area-Dachigam National Park with study sites marked by a grid

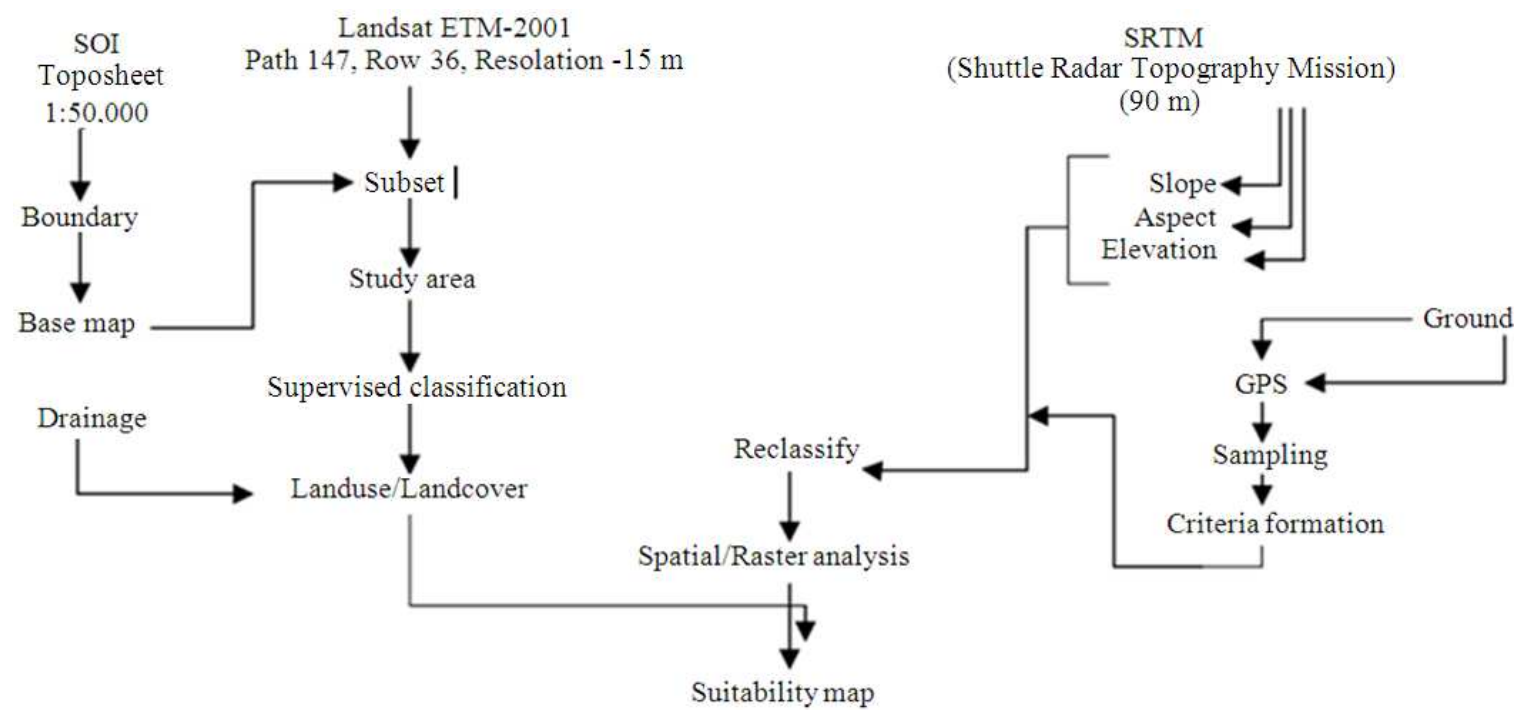

Fig. 3. Algorithms of the methodology used for the development of the habitat suitability model 


\section{RESULTS}

During field surveys, the aspects favorable to musk deer were found to vary between $293^{\circ}$ Northwest$68^{\circ}$ Northeast. Similarly, slope gradients of $25^{\circ}-40^{\circ}$ predominated in the musk deer habitats. The musk deer were found to occur from elevations of $2100 \mathrm{~m}$ and above but it also depended on the level of disturbance. If there are presumably no threats surmounting, musk deer could also extend their movements on to the lower elevations of up to $2000 \mathrm{~m}$ asl.

Figure 4a, $4 \mathbf{c}$ and $4 \mathbf{e}$ respectively are the aspect, slope gradient and digital elevation model of the study area, Dachigam National Park, while the topographic information found important in the musk deer habitats is highlighted in Fig. $4 \mathbf{b}, \mathbf{d}$ and $\mathbf{f}$. From the aforementioned set criteria and rules, the habitat suitability map for the musk deer as developed is presented (Fig. 5) and the spatial distribution of the musk deer in Dachigam National Park is explored (Fig. 6). The spatial distribution of musk deer reflects the musk deer habitats mostly spread through the Picea smithiana and blue pine forest and some habitats close to the alpine scrub nearby to the rocky cliffs.

An estimated 60 musk deer survive in Dachigam National Park, as calculated from the habitat suitability model and hence, the density of musk deer for whole National Park is 0.42 individuals per sq. $\mathrm{km}$. (445 points were generated for the whole National Park. The number of points generated within the study sites Zahil, KungWattan, KawNar and KutNar equals 45 points. In other words, 45 points corresponded to 6 individuals and hence 445 points will correspond to 59.33 or 60 individuals. Accordingly, density in the 141 sq. $\mathrm{km}$. area (of DNP) equals 0.42 individuals $/ \mathrm{km}^{2}$ ). However, the weighted mean density of musk deer in the musk deer habitat of Dachigam National Park is 1.55 individuals per sq. $\mathrm{km}$. (The weighted mean density of musk deer at the study sites Zahil, KungWattan, KawNar and KutNar is: $\{2$ Individuals $\times 1.88$ sq. $\mathrm{km}+1$ individual $\times 1.41 \mathrm{sq}$. $\mathrm{km}+2$ individuals $\times 1.05$ sq. $\mathrm{km}+1$ individual $\times 0.90$ sq. $\mathrm{km}\} /\{1.88$ sq. $\mathrm{km}+1.41$ sq. $\mathrm{km}+1.05$ sq. $\mathrm{km}$ +0.90 sq. $\mathrm{km}\}=1.55$ individuals per sq. $\mathrm{km}$ ).

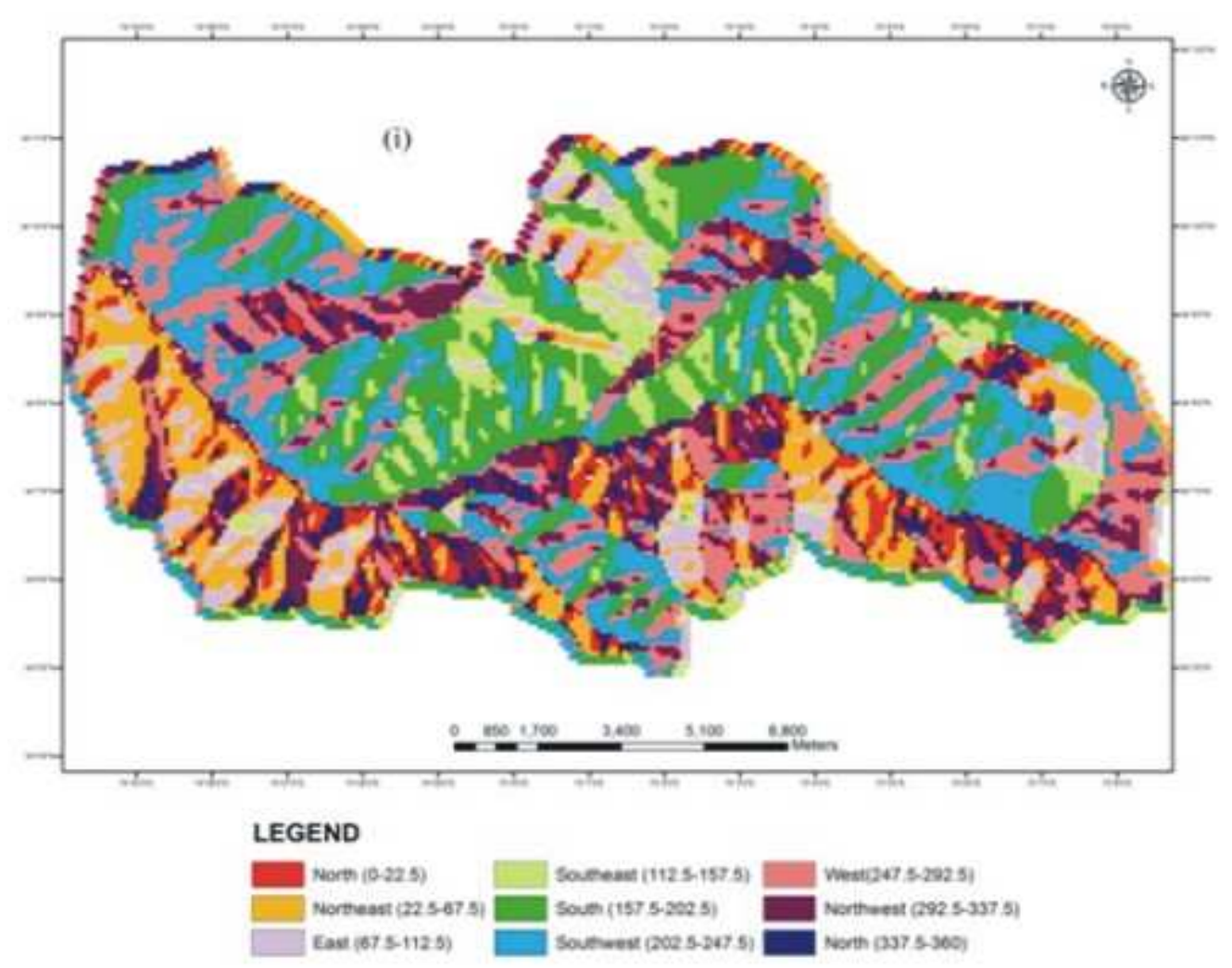

(a) 
Mudasir Ali / American Journal of Environmental Sciences 10 (5): 446-457, 2014

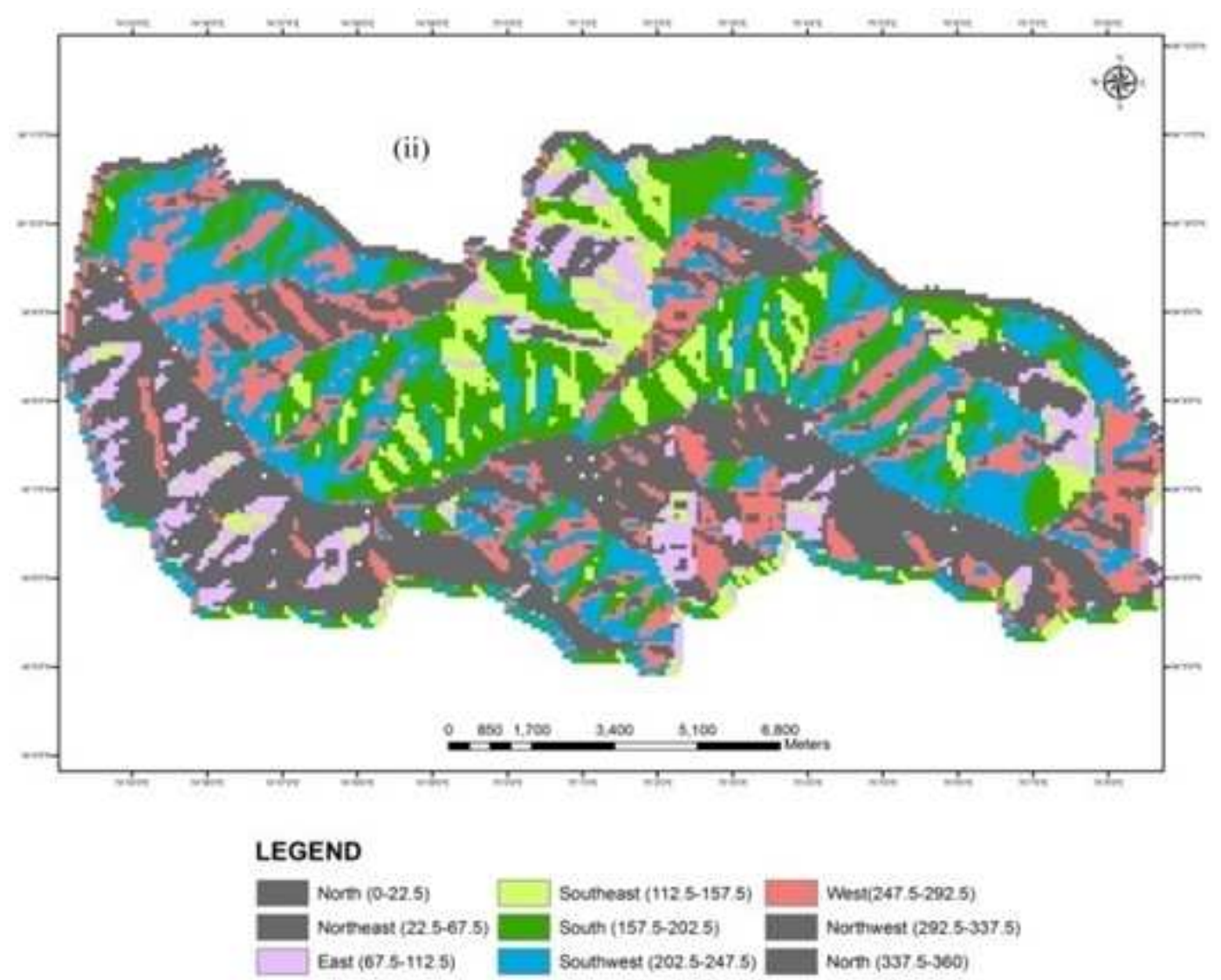

(b)

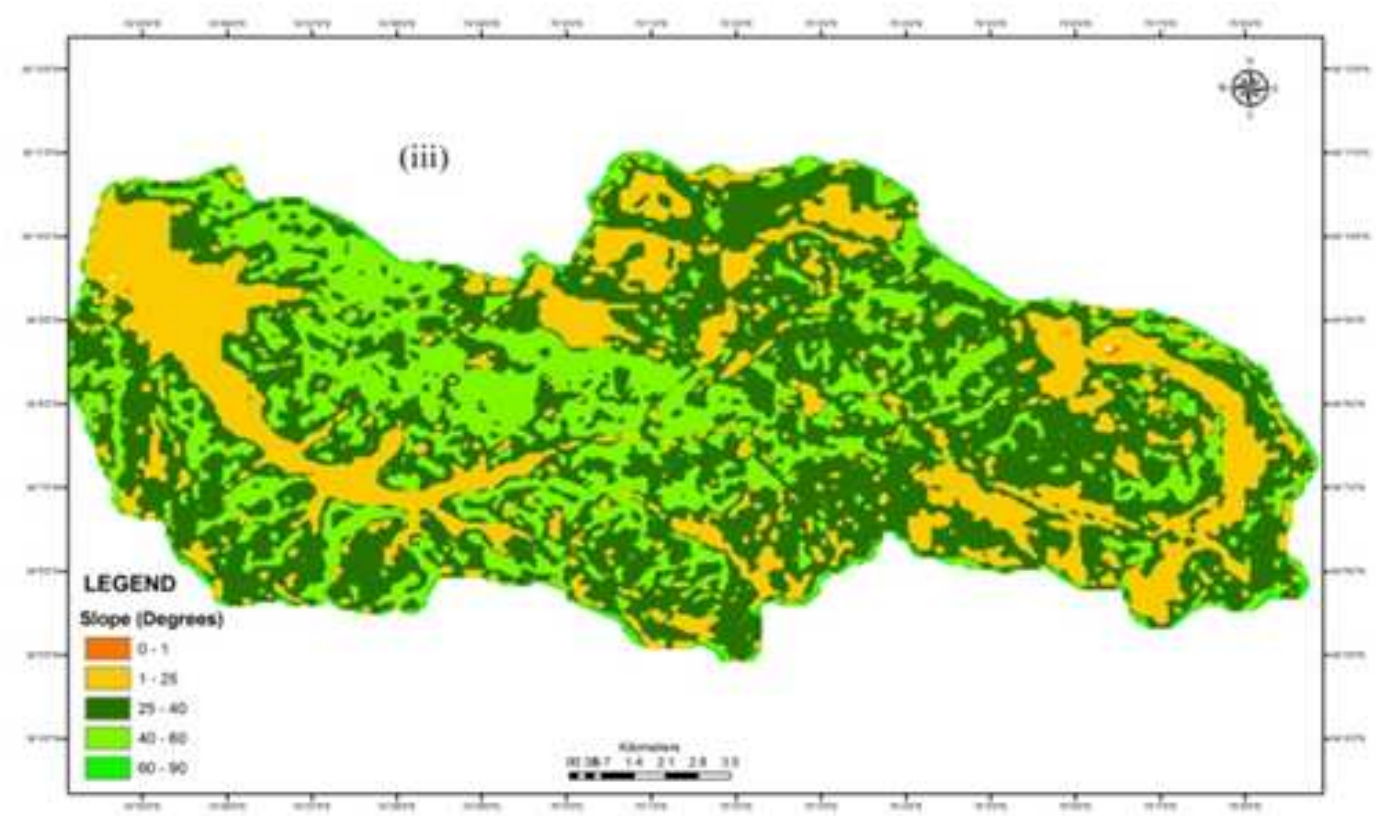

(c) 
Mudasir Ali / American Journal of Environmental Sciences 10 (5): 446-457, 2014

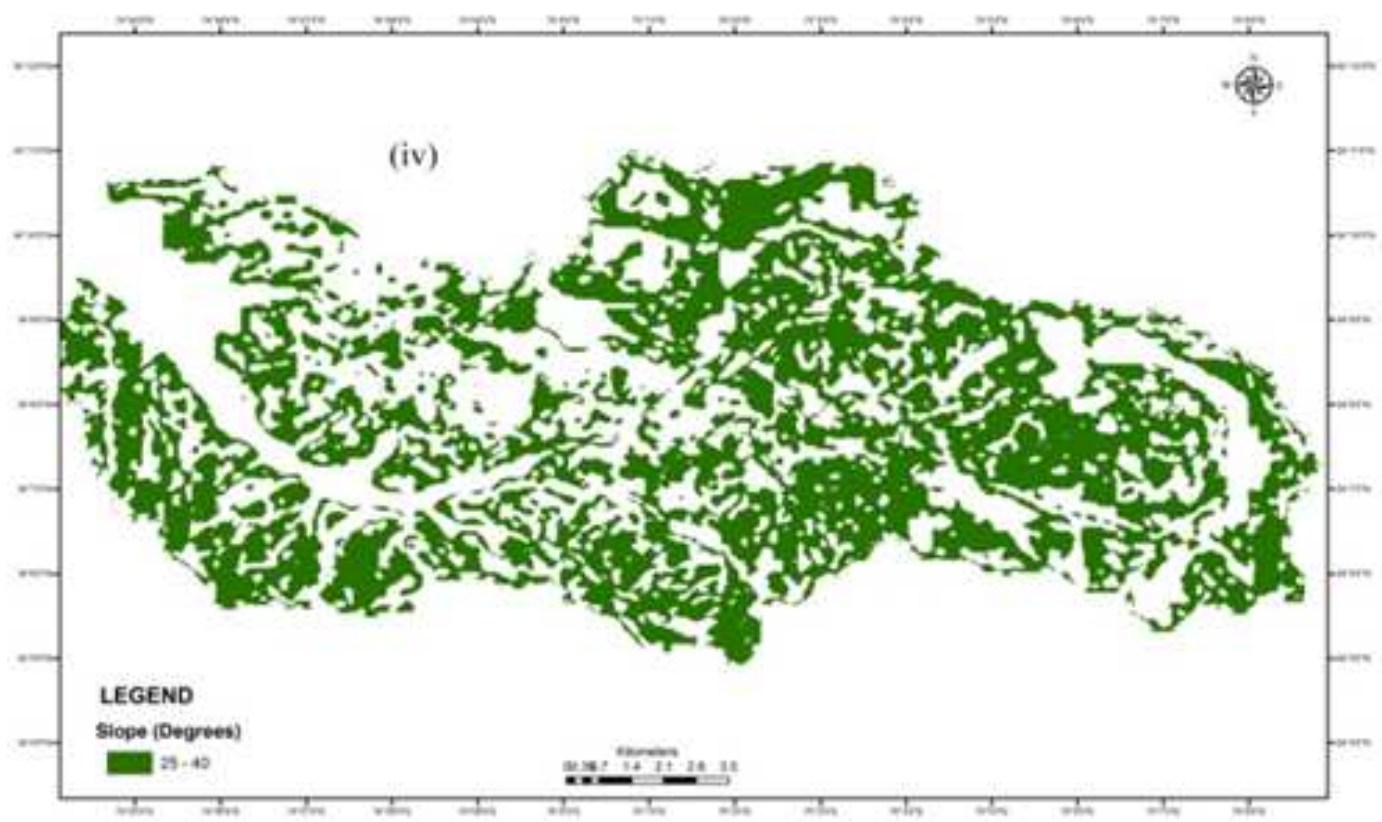

(d)

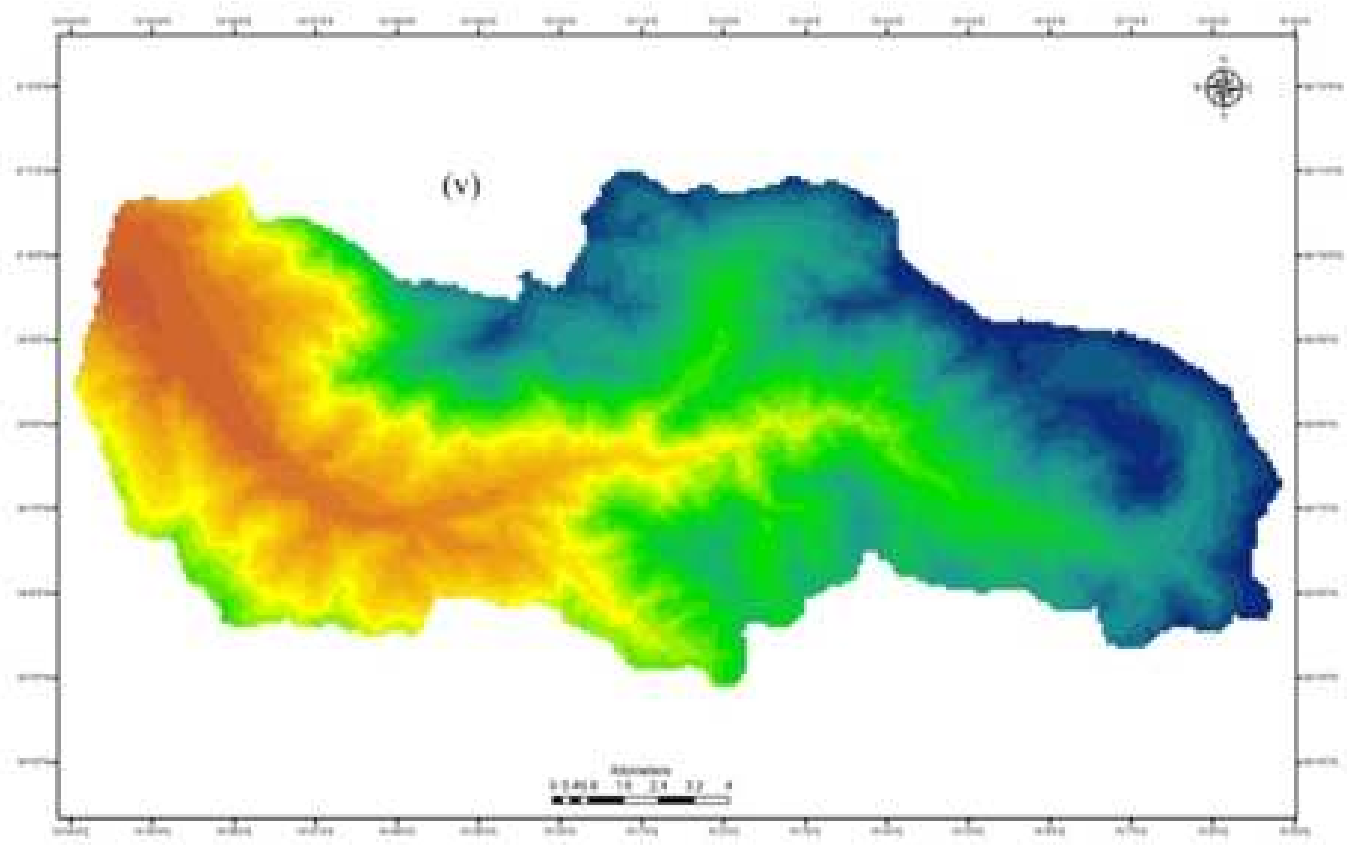

\begin{tabular}{|c|c|c|c|c|c|}
\hline LEGEND & $1,1,00-1,000$ & $2,500 \cdot 2,4,000$ & $2.000-2.1000$ & $3,300+1,400$ & I $1900-2000$ \\
\hline Elevation $(m)$ & $1900-2.900$ & $2,400+2,500$ & $2.900-3.000$ & $3,400-3,500$ & I $3,400+4,000$ \\
\hline 1,000 & $2,000-2,100$ & $2,000 \cdot 2,000$ & $2,000 \times 3,100$ & $3500 \cdot 3.000$ & $1,0000=4,200$ \\
\hline $1,000+1,700$ & $2.100 \cdot 2.200$ & $2,000+2,700$ & $2,100 \cdot 3,500$ & $2000+3700$ & \\
\hline 1700,1000 & $2300-2300$ & $2700-2.000$ & $2.300-2.390$ & $3700+2,000$ & \\
\hline
\end{tabular}

(e) 
Mudasir Ali / American Journal of Environmental Sciences 10 (5): 446-457, 2014

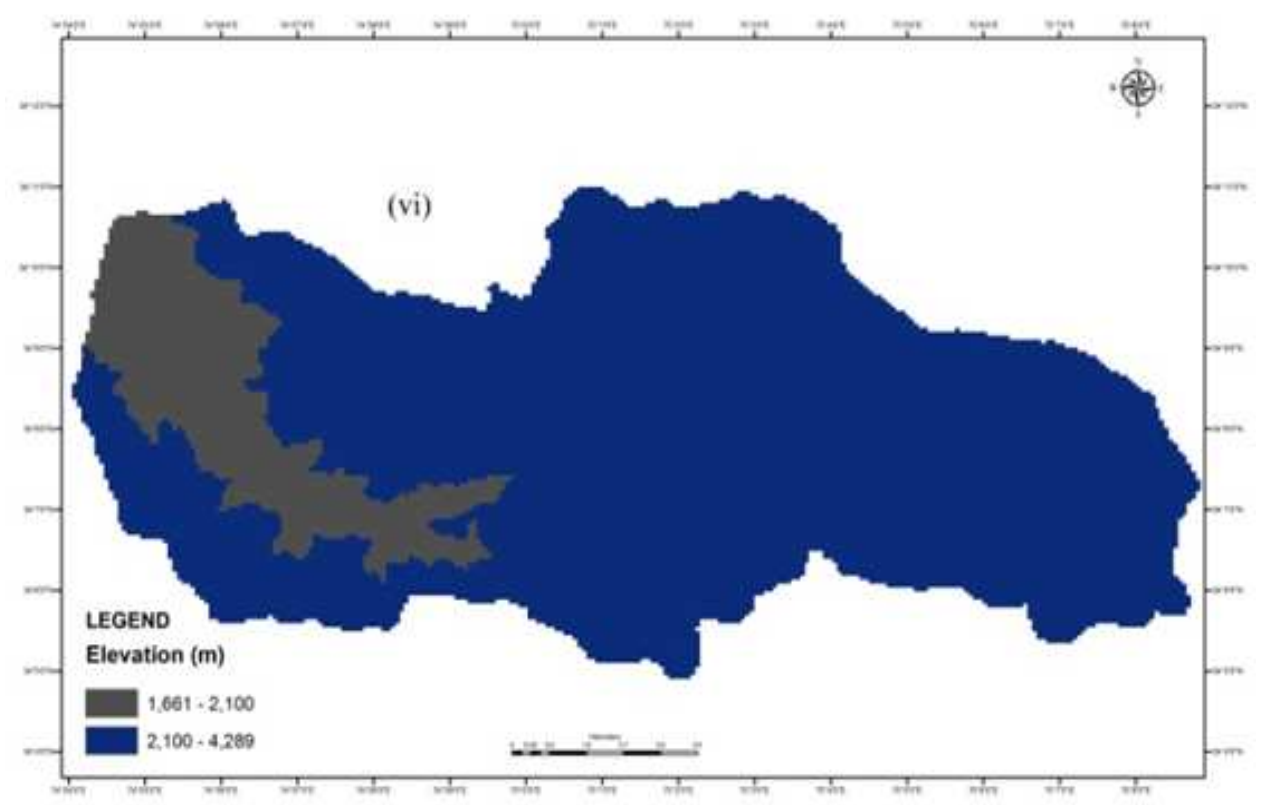

(f)

Fig. 4. Aspect, slope gradient and digital elevation model of the study area, Dachigam National Park and the highlighted topographic information found important for the development of the habitat suitability map for the exploration of the potential distribution of the Kashmir musk deer. (a) Aspect map (b) Aspects favorable to Kashmir musk deer clubbed together $\left(293^{\circ}\right.$ Northwest$68^{\circ}$ Northeast) in a single color notation (c) Slope gradient map (d) favorable slopes $\left(25^{\circ}-40^{\circ}\right)$ to Kashmir musk deer highlighted (e) Digital elevation model of the study area (f) Elevations favorable to Kashmir musk deer highlighted (2100 $\mathrm{m}$ and above)

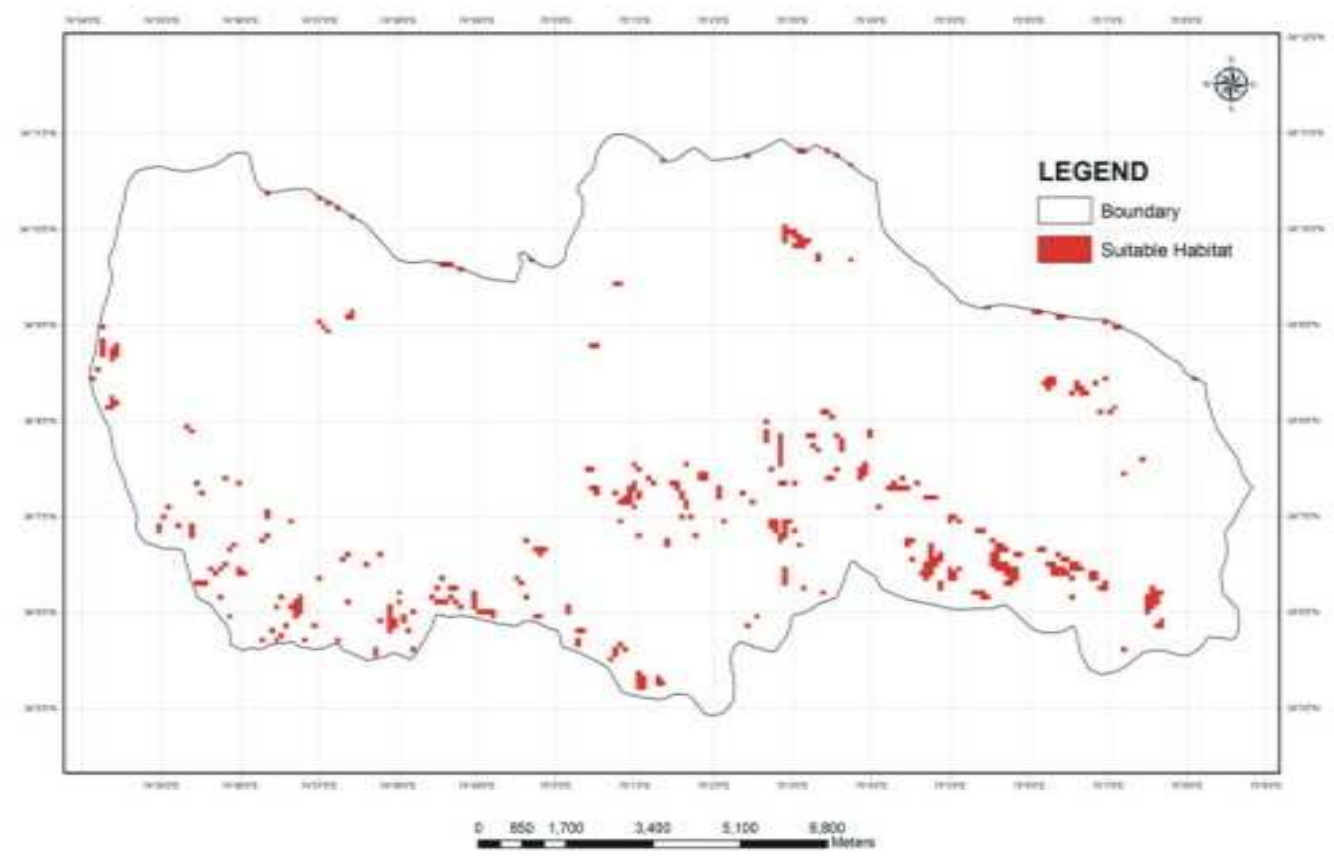

Fig. 5. Current habitat suitability model generated for the Kashmir musk deer 


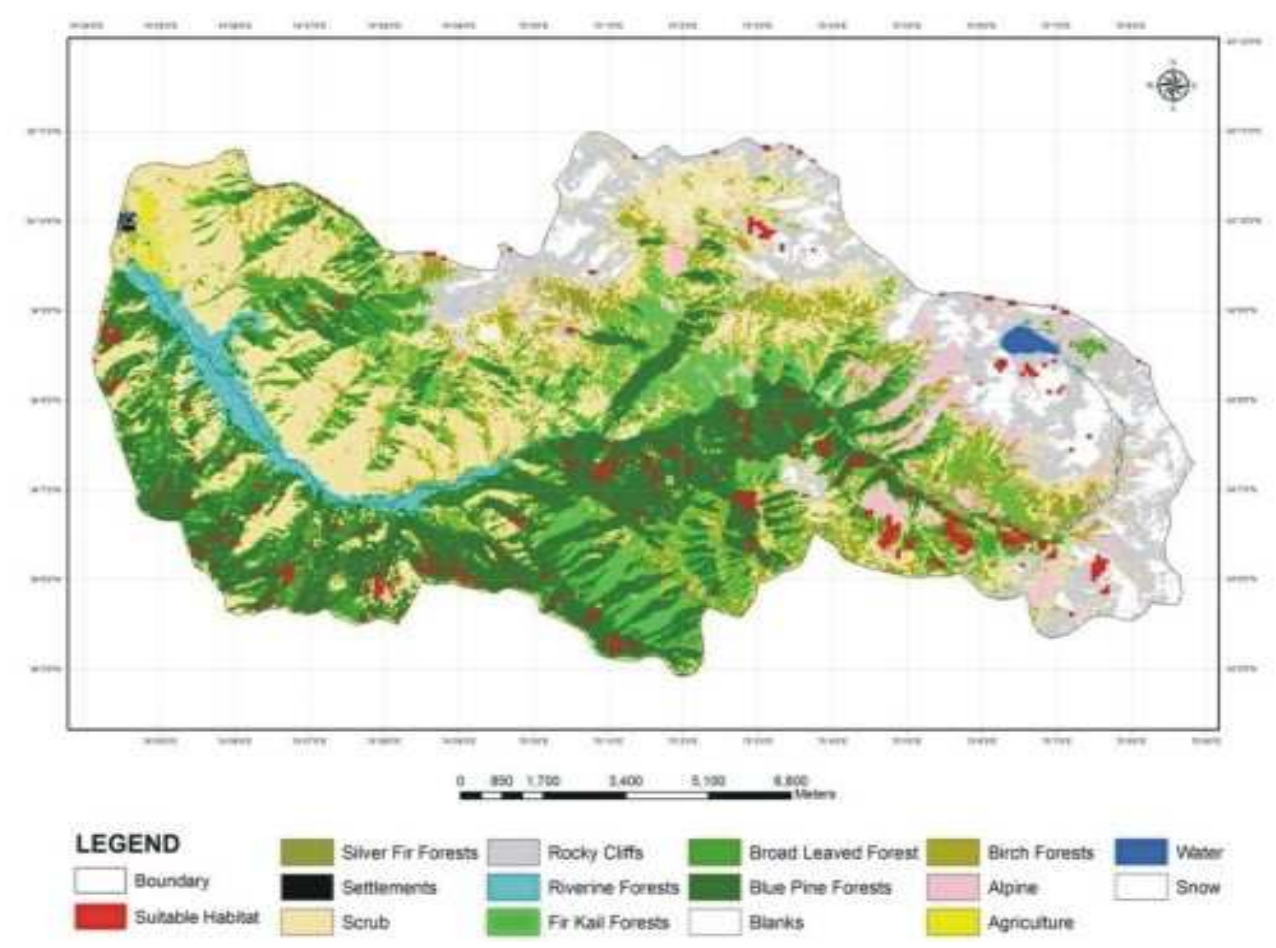

Fig. 6. Habitat suitability map overlaid on the landcover map, predicting the spatial distribution of the Kashmir musk deer (Moschus cupreus) in Dachigam National Park, Kashmir

From the habitat suitability map so developed, the current suitable musk deer habitat in Dachigam National Park is estimated in the extent of about $40 \mathrm{sq} . \mathrm{km} .(\sim 28 \%$ area of the national park).

\section{DISCUSSION}

Field evaluation of the different habitats in Dachigam National Park for finding the distribution of musk deer gave a general understanding that aspect or exposure of the slope was somehow a highly important factor in governing the occurrence of the musk deer in the habitat. The steepness of the slope was found to be another very important factor in predicting the presence of the musk deer. The slope and elevation appear to be interrelated. The steeper slopes are usually associated with the higher elevations, especially on the northerly aspects. Therefore this factor appears to be more important than the elevation. Giving higher preference to altitude than slope seems tempting but the slope offers both the advantages (steepness as well as higher elevation) linking the suitability of the habitat with the environmental attributes. Altitude was found to have a lower significance in comparison to the aspect and slope gradient which was also tested during model building when altitude was given higher preference over slope gradient leading however to the false predictions.

Notwithstanding that the habitat suitability model developed is surely a 'presence-only' model and there are no counterbalancing absences but such type of models have now been proven to correlate well with 'presence-absence' models. Errors of over prediction have also been found to be avoided in such models. Moreover, only predictor or major governing factors have been worked out and used in the predictions due to which the problems associated with incorporation of noise by using too many data layers has been avoided. This type of model can be easy to run after the major governing factors at the study sites are carefully evaluated.

Since, in a habitat not all areas are equally important and just some areas or microsites are favorable and others may be avoided. This type of issue is tackled in this model. Most of the surveys for evaluating the density of the animals work out the density in the habitat of the animal and then erroneously apply it to whole of the study area. For example, the density of musk deer in Dachigam National Park was reported as 0.4 animals per sq. km., 
based on the sign of only two animals found within a $5.4 \mathrm{~km}^{2}$ surveyed area, according to (Green, 1986). But this generalization has failed to notice that a large portion of the National Park has southern aspect which is unsuitable for musk deer (Fig. 4). The timidity of musk deer, combined with their remote habitats, means that there are very few accurate population estimates (WWF, 2002).

The model results were found to have a good performance in making fair predictions because only those areas have been predicted which were found during the survey to harbor the musk deer and also no absence patch has been predicted to contain the musk deer (about $50 \%$ area of the National Park has been validated for predictions). These inferences validate the genuineness of the developed model for the prediction of spatial distribution and occurrence of musk deer. However, applying such type of model outside of the protected area could give false predictions because the habitats or the populations might have been affected by the anthropogenic disturbances.

Models abbreviate reality, enabling us to analyze the workings of a system, or to make predictions about its behaviour (Beeby and Brennan, 2008). Habitat suitability models statistically relate field observations to a set of environmental variables, presumably reflecting some key factors of the niche, like climate, topography, geology, or land-cover. They produce spatial predictions indicating the suitability of locations for a target species, community or bio-diversity (Hirzel et al., 2006). As they often help both in understanding species niche requirements and predicting species potential distribution, their use has been especially promoted to tackle conservation issues, such as managing species distribution, assessing ecological impacts of various factors (e.g., pollution, climate change), risk of biological invasions or endangered species management (Scott et al., 2002; Guisan and Thuiller, 2005).

Although the main problem of presence-only evaluation measures is the lack of absences to counterbalance the presences, however, the presence-only evaluators have been shown to fairly correlate $(\rho>0.7)$ to the presence/absence ones (Hirzel et al., 2006). The influence of topography is intimately connected with the other abiotic factors (Taylor and Tomkins, 1990). Peterson and Kluza (2003) used the environmental data coverage and a subset of occurrence information for developing Generic Algorithm for Rule-Set Prediction (GARP) models based principally on topographic and climatic information with conclusions reflecting avoidance of overprediction errors in the pointbased approach or occurrence data. Field data on landform characteristics (e.g., elevation, slope, aspect, exposure, net curvature of slope) has been explored for the development of habitat suitability index models by (Fels, 1994; Mitchell, 1997; Mitchell et al., 2002) and many other researchers.

Most habitat suitability models (including GLMs) generate maps showing continuous gradients of suitability, however, a reclassified map showing only a few classes may be more honest about its actual informative content (Hirzel et al., 2006). The model's evaluation consists in quantifying how accurately the map is predicting the presence and absence of the species (Buckland and Elston, 1993; Manel et al., 2001), as given by a set of evaluator points-which may consist either of verified presences and absences, or of verified presences only (Hirzel et al., 2006).

Therefore, in lieu of the aforementioned literature and the field observations, it can be emphasized that the currently developed model has made a fair prediction of the spatial distribution of the Kashmir musk deer in Dachigam National Park and the potential utility of the model to find the density of the animal is possible.

\section{CONCLUSION}

The presently studied habitat modeling approach can be helpful in tackling conservation issues concerning the endangered species management, management of the species distribution as well as in the understanding of the species niche requirements.

\section{ACKNOWLEDGEMENT}

The Department of Wildlife (Protection), Jammu and Kashmir Government is highly acknowledged for the grant of permission to carry out the study within and beyond Dachigam National Park. Prof. G.A. BhatResearch Supervisor (University of Kashmir), Dr. William J. McShea (Smithsonian Institution, VA, USA/IUCN SSC Deer Specialist Group), Prof. Colin P. Groves (Australian National University Canberra, Australia), Dr. S.S. Sathyakumar (Wildlife Institute of India) and Dr. Michael J.B. Green (World Conservation Monitoring Centre, Cambridge, UK) are keenly thanked for sharing their valuable research papers, thoughts or precious time. Mr. Majid Farooq (Department of Environment and Remote Sensing, Srinagar) is duly appreciated for his help in the geospatial analyses. I am also grateful with the Anne Zimmermann (Centre for Development and Environment, University of Berne, Switzerland) who considerably improved the quality and scope of this study through her worthy insight and meaningful suggestions. 


\section{REFERENCES}

Akawwi, E., 2013. Geomorphology using geographic information system and global mapper. Am. J. Environ. Sci., 9: 398-409. DOI: 10.3844/ajessp.2013.398.409

Alfred, R., A.H. Ahmad, J. Payne, C. William and L. Ambu, 2010. Density and population estimation of the bornean elephants (Elephas maximus borneensis) in Sabah. OnLine J. Biol. Sci., 10: 92102. DOI: $10.3844 /$ ojbsci.2010.92.102

BOSTID, 1991. Microlivestock: Little-Known Small Animals with a Promising Economic Future. 1st Edn., National Academy Press, Washington, D.C., pp: 313.

Beck, M.B., 1983. Uncertainty, System, Identification and the Prediction of Water Quality. In: Uncertainty and Forecasting of Water Quality, Beck, M.B. and G. Van Straten, (Eds.), Springer-Verlag, New York, ISBN-10: 978-3-642-82056-4, pp: 3-68.

Beeby, A. and A.M. Brennan, 2008. First Ecology: Ecological Principles and Environmental Issues. 3rd Edn., Oxford University Press Inc., New York, ISBN-10: 9780199298082, pp: 577.

Bond, J.E., D.A. Beamer, T. Lamb and M. Hedin, 2006. Combining genetic and geospatial analyses to infer population extinction in mygalomorph spiders endemic to the Los Angeles region. Anim. Conservat., 9: 145-157. DOI: 10.1111/j.14691795.2006.00024.x

Buckland, S.T. and D.A. Elston, 1993. Empirical models for the spatial distribution of wildlife. J. Applied Ecol., 30: 478-495. DOI: 10.2307/2404188

Burton, M. and R. Burton, 1990. The Marshal Cavendish International Wildlife Encyclopedia. Ist Edn., Marshal Cavendish Corporation, New York, pp: 2899.

Cale, W.G., 1995. Model Aggregation: Ecological perspectives. In: Complex Ecology: The Part-whole Relation in Ecosystems, Patten, B.C. and S.E. Jorgensen (Eds.), Prentice Hall, Englewood Cliffs, ISBN-10: 0131615068, pp: 230-241.

Choudhury, S., M. Ali, T. Mubashir, S.N. Ahmad and M.N. Sofi et al., 2008. Predator alert-attacks on humans by leopards and asiatic black bear in the kashmir valley-analysis of case studies and spatial patterns of elevated conflict. Wildlife Trust of India.

DeAngelis, D.L., L.W. Barnhouse, W. Van Winkle and R.G. Otto, 1990. A critical appraisal of population approaches in assessing fish community health. J. Great Lakes Res., 16: 576-590. DOI: 10.1016/S0380-1330(90)71446-3
Demaría, M.R., W.J. McShea, K. Koy and N.O. Maceira, 2003. Pampas deer conservation with respect to habitat loss and protected area considerations in San Luis, Argentina. Biol. Conservat., 115: 121-130. DOI: 10.1016/S0006-3207(03)00101-0

Fels, J.E., 1994. Modeling and mapping potential vegetation using digital terrain data. $\mathrm{PhD}$ Thesis, North Carolina State University, Raleigh, USA.

Gergan, S.S., 1962. Big Game of Jammu and Kashmir. 1st Edn., The Game Warden, Press, Srinagar.

Green, M.J.B., 1986. The distribution, status and conservation of the himalayan musk deer moschus chrysogaster. Biol. Conservat., 35: 347-375. DOI: 10.1016/0006-3207(86)90094-7

Guisan, A. and W. Thuiller, 2005. Predicting species distribution: Offering more than simple habitat models. Ecol. Lett., 8: 993-1009. DOI: 10.1111/j.1461-0248.2005.00792.x

Hirzel, A.H., G.L. Lay, V. Helfer, C. Randin and A. Guisan, 2006. Evaluating the ability of habitat suitability models to predict species presences. Ecol. Modell., 199: 142-152. DOI: 10.1016/j.ecolmodel.2006.05.017

Jones, J.C. and J.D. Reynolds, 1996. Environmental variables. In: Ecological Census Techniques: A Handbook, Sutherland, W.J. (Ed.), Cambridge University Press, Cambridge, ISBN-10: 0521478154, pp: 281-316.

Koy, K., W.J. McShea, P. Leimgruber, B.N. Haack and M. Aung, 2005. Percentage canopy cover-using Landsat imagery to delineate habitat for Myanmar's endangered Eld's deer (Cervus eldi). Anim. Conservat., 8: 289-296. DOI: 10.1017/S1367943005002209

Lawrence, W.R., 1895. The Valley of Kashmir. H. Frowde, London.

Lillesand, T.M. and R.W. Kiefer, 1994. Remote Sensing and Image Interpretation. 3rd Edn., Wiley and Sons, The University of Michigan, New York, ISBN-10: 0471577839, pp: 750.

Ludwig, D. and C.J. Walters, 1985. Are age-structured models appropriate for catch-effort data? Canadian. J. Fisheries Aquatic Sci., 42: 1066-1072. DOI: 10.1139/f85-132

Madugundu, R., K.A. Al-Gaadi, V.C. Patil and E. Tola, 2014. Detection of land use and land cover changes in Dirab region of Saudi Arabia using remotely sensed imageries. Am. J. Environ. Sci., 10: 8-18. DOI: 10.3844/ajessp.2014.8.18 
Manel, S., H.C. Williams and S.J. Ormerod, 2001. Evaluating presence-absence models in ecology: The need to account for prevalence. J. Applied Ecol., 38: 921-931. DOI: 10.1046/j.1365-2664.2001.00647.x

McShea, W.J., P. Leimgruber, M. Aung, S.L. Monfort and C. Wemmer, 1999. Range collapse of a tropical cervid (Cervus eldi) and the extent of remaining habitat in central Myanmar. Anim. Conservat., 2: 173-183. DOI: 10.1111/j.1469-1795.1999.tb00063.x

Mitchell, M.S., 1997. Optimal home ranges: Models and application to black bears. $\mathrm{PhD}$ Thesis, North Carolina State University, Raleigh, USA.

Mitchell, M.S., J.W. Zimmerman and R.A. Powell, 2002. Test of a habitat suitability index for black bears in the southern Appalachians. Wildlife Soci. Bulletin, 30: 794-808.

Peterson, T.A. and D.A. Kluza, 2003. New distributional modelling approaches for gap analysis. Anim. Conservat., 6: 47-54. DOI: 10.1017/S136794300300307X

Powell, R.A., J.W. Zimmerman and D.E. Seaman, 1997. Ecology and Behaviour of North American Black Bears: Home Ranges, Habitat and Social Organization. 1st Edn., Springer Science and Business Media, United Kingdom. ISBN-10: 0412788306, pp: 203.
Rastetter, E.B., A.W. King and B.J. Cosby, 1992. Aggregating fine-scale geological knowledge to model coarser-scale attributes of ecosystems. Ecol. Appli., 2: 55-70. DOI: 10.2307/1941889

Schaller, G.B., 1989. Mountain Monarchs: Wild Sheep and Goats of the Himalaya. 1st Edn., University of Chicago Press, Chicago. ISBN-10: 0226736512, pp: 425.

Scott, J.M., P.J. Heglund and M.L. Morrison, 2002. Predicting Species Occurrences: Issues of Accuracy and Scale. 1st Edn., Island Press, Washington, ISBN-10: 1597263052, pp: 840.

Stelfox, H.A., 1991. Assessing Land/Wildlife Relationships Via the Ecological Land Evaluation. In: Guidelines for the Integration of Wildlife and Habitat Evaluations with Ecological Land Surveys, 1st Edn., Wildlife Habitat Canada, University of Minnesota, pp: 107.

Taylor, R. and S. Tomkins, 1990. Organisms and their Environment. In: Biological Science, Green, N.P.O., G.W. Stout, D.J. Taylor and R. Soper (Eds.), Cambridge University Press, pp: 359-438.

WWF, 2002. Musk deer Moschus spp. Proceedings of the 12th Meeting of the Conference of the Parties to CITES Santiago, Nov. 3-15. 